\title{
Prática desportiva, um meio de prevenção do bullying na escola?
}

\author{
Fernando Marcelo Ornelas Melim* \\ Beatriz Oliveira Pereira**
}

\begin{abstract}
Resumo: Pretende-se averiguar se a participação desportiva dos alunos (escolar ou federada) diminui a probabilidade de envolvimento em situações de bullying durante a sua permanência na escola. Estudo analítico de delineamento transversal realizado numa amostra de 1818 alunos de escolas portuguesas, com uma média de idades de 12,8 anos. Utilizouse um questionário sobre comportamentos de bullying, adaptado de Olweus (1989), ao qual foram acrescentados tópicos sobre a participação desportiva dos alunos. Concluímos que a influência do desporto a este nível fica aquém do esperado. Porém, aspetos como o género dos praticantes e o tipo de modalidades praticadas influem nos resultados alcançados.
\end{abstract}

Palavras-chave: bullying. Escola. Desporto. Vítimas. agressores

\section{INTRODUÇÃo}

Através do desporto, o jovem tem a oportunidade de aprender a cooperar e a competir saudavelmente, respeitar os outros e adquirir um comportamento moral e ético (COSTA; PEREIRA; SILVÉRIO, 2008; QUEIRÓS; GOMES; SILVA, 2008). Todavia, não é a competição ou o tipo de desporto praticado que determinam automaticamente o valor das referidas atividades desportivas. É antes a natureza das experiências e aprendizagens vividas nessas atividades e as interações com os demais envolvidos no processo (pares, os

\footnotetext{
"Professor destacado pela Secretaria Regional de Educação e Recursos Humanos da Região Autónoma da Madeira, Universidade do Minho, Portugal. E-mail: marcelomelim@ie.uminho.pt "Professora Catedrática do Instituto de Educação, Universidade do Minho, Portugal, E-mail: beatriz@iec.uminho.pt
} 
treinadores, os professores e os pais), que vão determinar se a prática de atividades desportivas contribui ou não para a aquisição de valores e atitudes que se pretendem alcançar (COSTA; PEREIRA; SILVÉRIO, 2008).

O objetivo deste estudo é verificar se a vertente socializadora do desporto condiciona favoravelmente o comportamento dos alunos face ao problema do bullying, seja na perspetiva de vitimização ao fornecer-lhe confiança para uma resposta mais assertiva perante as tentativas de agressão, seja na perspetiva da agressão, reduzindo significativamente esta forma negativa de interação com os pares. Pretendemos, simultaneamente, averiguar se esta relação varia em função da natureza das modalidades desportivas praticadas pelos jovens alunos.

Como depreendemos dos objetivos traçados, as principais variáveis em estudo nesta investigação são precisamente a vitimização e agressão por bullying e a participação em atividades desportivas, tanto escolares como federadas.

\section{COMPORTAMENTO BULLYING}

O bullying pode ser visto como uma subcategoria do comportamento agressivo mas de um tipo particularmente mau e cruel, isto porque é dirigido a uma vítima que é incapaz de se defender sozinha de forma eficaz. Os ataques são na sua maioria sem motivo ou pelo menos não são provocados e têm por objetivo magoar ou ferir a criança ou jovem alvo. As crianças vítimas provavelmente serão mais novas, mais fracas ou simplesmente, menos confiantes psicologicamente. A criança agressora utiliza este comportamento de forma a infligir dano e através disso obter uma gratificação psicológica, status no grupo de pares ou, por vezes, ganho financeiro direto, ao obter dinheiro ou outras quaisquer posses da vítima (SMITH; MONKS, 2008).

Felix e Green (2010), destacam que a diferença de poder numa relação em que exista bullying pode apresentar várias formas, de 
acordo com as origens desse poder, e que podem incluir a força física, a popularidade, pertencer a uma maioria ou grupo privilegiado e/ou possuir habilidades cobiçadas (por exemplo, atléticas ou académicas).

No âmbito deste trabalho assumimos como definição operacional de bullying, a agressão entre jovens, intencional e frequente, capaz de causar danos ou magoar, tais como: ameaçar, chantagear, chamar nomes, gozar, levantar falsos testemunhos, contar segredos, praxar de forma violenta, pôr de parte um(a) colega, ignorálo (a), bater, empurrar e tirar objetos de valor. O ciberbullying, em particular, corresponde ao bullying que é realizado através do uso de tecnologia, tal como telemóveis e internet.

\section{DESPORTO COMO FATOR DE EXCLUSÃO E DE POTENCIALIZAÇÃO DO COMPORTAMENTO BULLYING}

A vivência do desporto pela criança não deve ser entendida "em si", ou seja, desligada do contexto histórico e social do qual se insere. $\mathrm{O}$ contexto histórico do desporto atual na nossa sociedade é o do desporto espetáculo, onde se valoriza a vitória a qualquer custo e o alto-rendimento, desvalorizando os menos habilidosos (Neto, 1994). Este autor questiona se o desporto estará a ser apresentado aos jovens com os mesmos valores do desporto espetáculo que é veiculado pelos média ou está a ser adaptado às necessidades e aos anseios das crianças?

De acordo com Escury e Dudink (2010), apesar do papel do desporto ser considerado importante como contributo para uma vida saudável, incluindo a estimulação do desenvolvimento motor, da agilidade, da aptidão física geral, o bem-estar psicológico, o trabalho de equipa, a autoconfiança, a assertividade, a lealdade e amizade, este contém igualmente um risco da criança ser vitimada por bullying, o que por sua vez afetará a autoconfiança, aumentará o comportamento submisso e a atitude de renuncia. As características do desporto que podem incrementar o risco do bullying ocorrer, 
assentam na sua natureza competitiva, nas terríveis seleções que ocorrem, no facto das suas regras poderem não ser claras para todos, etc.

No entendimento de alguns autores (ENDRESEN; OLWEUS, 2005; ESCURY; DUDINK, 2010), a maioria das crianças que é vítima da bullying na escola também o é durante a prática desportiva nos clubes. $\mathrm{O}$ desporto pode não ser necessariamente um aliado contra o bullying, pelo contrário, participar no treino desportivo pode acarretar alguns riscos no que respeita à vulnerabilidade ao bullying. Os riscos podem residir em vários aspetos: os treinadores interferem menos; as crianças podem ter a tendência de relatar menos as situações de bullying aos treinadores (em comparação com os professores na escola); as crianças podem sentir-se intimidadas pelos próprios treinadores; e os treinadores podem estar menos sensibilizados para as questões do bullying.

No estudo de Peguero (2008), o objetivo foi investigar a relação entre a vitimização através de bullying e a participação dos alunos em atividades extracurriculares. Esta investigação examinou se o envolvimento dos estudantes em certas atividades escolares, tais como desportos, clubes, ateliers, bandas, etc., aumentava ou diminuía a sua probabilidade de serem agredidos/bullied durante a sua permanência na escola. Chegou-se à conclusão de que os alunos que participavam em atividades desportivas que decorriam no interior da escola tinham mais probabilidades de serem agredidos/bullied do que os alunos que não participavam nestas atividades. Por outro lado, os alunos que participavam em atividades desportivas que decorriam fora da escola tinham menos probabilidades de serem agredidos/bullied do que os colegas que não participavam nestas atividades. Estes resultados também sugerem que os alunos que permanecem na escola por extensos períodos de tempo têm uma probabilidade acrescida de serem vitimados através de bullying.

Mesmo fora do ambiente formal das atividades extracurriculares os alunos têm atitudes de exclusão nas suas práticas corporais em grupo. Higgins (1994) observou que aqueles alunos que não sobressaem relativamente às suas habilidades para os chamados 
jogos dominantes são visivelmente excluídos porque têm pouca oportunidade de participar em outras atividades mais solitárias durante o recreio. As vítimas de bullying são frequentemente aqueles que parecem diferentes dos seus pares. Se ser "normal" significa a capacidade de jogar futebol ou outro determinado jogo, então aqueles que não podem ou não querem jogar podem estar propensos ao bullying. Todos sabemos como se saem mal nos recreios os jovens mais solitários e fisicamente menos ativos e fortes.

Os rapazes mais aptos que tendem a dominar os recreios com vigorosos jogos de futebol, acabam forçosamente por marginalizar os outros alunos (muitas vezes as meninas e as crianças mais novas) e as suas atividades. Uma vez que não há uma disposição adequada ou proteção aos jogos menos vigorosos ou espacialmente exigentes. Esta situação pouco contribui para encorajar uma atitude mais solidária e cooperativa entre os alunos durante o exercício de atividades físicas e desportivas (HIGGINS, 1994).

Numa abordagem diferenciada da relação entre bullying e desporto que visamos no nosso estudo, o recente trabalho de Escury e Dudink (2010) pode contribuir para acrescentar alguns aspetos pertinentes à temática em questão. Nesta pesquisa com uma amostra de 922 jovens desportistas holandeses, entre os 7 os 12 anos de idade, utilizou-se igualmente uma versão adaptada do questionário de Olweus. Os participantes foram selecionados a partir de 14 clubes de futebol e de 12 clubes de judo. Dos resultados alcançados destacamos que seis por cento das crianças reportaram estarem envolvidas em bullying durante a sua participação desportiva que ocorria duas a três vezes por semana, comparativamente, aos $20 \%$ que ocorriam na sua frequência diária da escola. A prevalência do bullying no judo e no futebol foi semelhante mas a percentagem de agressore/bullies no futebol é maior.

Os autores alertam que as diferenças entre a incidência de bullying no desporto e na escola podem ser enganadoras, uma vez que a participação semanal e o tempo despendido no desporto é consideravelmente menor do que aquele que é passado na escola. Por exemplo, ser agredido uma vez por semana no treino desportivo 
pode constituir uma agressão em $50 \%$ dos encontros semanais, enquanto que na escola a mesma frequência de bullying, constitui uma agressão por $20 \%$ dos dias de escola.

Os resultados desta investigação permitiram perceber igualmente que o bullying que ocorre no treino tem algumas características distintas do bullying na escola e que até pode variar em função da modalidade desportiva praticada. Os autores concluem que não sendo o desporto uma proteção garantida contra o bullying, quando encaminhamos uma criança para a prática desportiva como forma de superação das suas dificuldades sociais, é necessário ponderar qual a modalidade que melhor se ajusta às suas necessidades e características.

\section{A AÇÃO PREVENTIVA DO DESPORTO EM RELAÇÃO AO BULLYING}

A superação e a prevenção do bullying através de ações desenvolvidas nas atividades desportivas podem ser analisadas da perspetiva da possível vítima ou do presumível agressor:

Se um jovem é vítima de bullying o importante será dotá-lo de determinadas competências pessoais e sociais que lhe permitam saber lidar da melhor forma possível com esse tipo de abuso ou constrangimento. Na opinião de Olweus (1993), é desejável, caso exista um mínimo de interesse nesse sentido, que as crianças vitimadas empreendam algum tipo de treino físico e que se tentem envolver em algum tipo de desporto adequado. Mesmo que as suas possibilidades de afirmação no desporto sejam limitadas, o exercício físico pode melhorar a coordenação motora e reduzir a ansiedade, o que melhorará a sua autoconfiança. Esta, por sua vez, leva a que a criança envie sinais diferentes para o seu meio, o que pode melhorar o seu relacionamento com os colegas.

No caso dos alunos agressores o benefício poderá advir de outras estratégias de ação a utilizar no âmbito da prática desportiva. As crianças que agridem/bully aprenderam a utilizar o seu poder de forma agressiva. Eles afirmam o seu poder social através da agressão. O desafio será então redirecionar o potencial dessas crianças ao 
nível da sua capacidade de liderança. Das estratégias negativas de bullying à liderança positiva, estas crianças necessitam de apoio para encontrar maneiras positivas de ganhar poder e status entre os seus pares (PEPLER et al., 2008).

Se os agressores/bullies possuem uma certa vantagem física e cognitiva social, então é capaz de ser possível canalizá-la para comportamentos mais adequados, como por exemplo permitir-lhes exercer um papel de liderança em atividades desportivas ou em atividades de apoio aos pares durante o treino, em vez de esta ser expressa através da prática do bullying (WOLKE et al., 2001).

\section{Método}

Estudo descritivo de delineamento transversal que incide sobre os níveis de participação desportiva e a sua associação com a prevalência de comportamentos de vitimização e agressão através bullying, nos alunos das escolas públicas dos $2^{\circ}$ e $3^{\circ}$ ciclos da Região Autónoma da Madeira (Portugal).

Uma amostra por clusters estratificada em meio rural e urbano. A amostra é constituída por 1.818 alunos, pertencentes a 88 turmas do $5^{\circ}$ ao $9^{\circ}$ anos de escolaridade, de três escolas públicas localizadas em três municípios da referida região autónoma. As idades dos alunos deste estudo estão compreendidas entre os 10 e os 18 anos, com $93,5 \%(n=1700)$ da amostra concentrada entre os 10 e os 15 anos. A média de idades situa-se nos 12,8 anos com um desvio padrão de 1,7. A amostra de acordo com o género é constituída por 914 raparigas $(50,3 \%)$ e 904 rapazes $(49,7 \%)$.

A técnica de recolha de dados usada neste estudo foi o inquérito por questionário. Foi utilizado um questionário original de Olweus (1989), adaptado para a língua portuguesa e validado para a população escolar portuguesa por Pereira e Tomás (1994 cit. em Pereira, 2008) e revisto para este estudo em 2010.

O questionário estava organizado em quatro secções, sendo a primeira relativa aos dados sociométricos, a segunda dizia respeito à 
identificação de comportamentos de vitimização por bullying, a terceira secção destinava-se à identificação de comportamentos de agressão por bullying e na quarta secção eram abordados tópicos sobre a participação desportiva dos alunos, nomeadamente, a sua participação escolar e federada, as modalidades praticadas e a respetiva duração.

O questionário foi aplicado no final do terceiro período do ano letivo 2009/2010. Todas as questões relativas ao bullying remetiam apenas para esse período letivo, diziam respeito a situações ocorridas em contexto escolar e não estavam especificamente relacionadas com qualquer atividade desportiva.

No tratamento dos dados e em relação às variáveis envolvimento no bullying e participação desportiva convencionou-se que a participação em fenómenos de bullying seria considerada desde que fosse registada pelo menos uma ocorrência durante o período estudado e não apenas quando tal ocorre duas ou mais vezes (DUE; HOLSTEIN, 2008; ESCURY; DUDINK, 2010). Este procedimento está em conformidade com estudos transnacionais, como o Health Behaviour in School-aged Childen - HBSC e o Global School-based Student Health Survey - GSHS. Ao nível da participação desportiva, esta apenas foi considerada a partir de um ano de prática consecutiva.

\section{ApresentaÇão dos resultados}

\subsection{PARTICIPAÇÃO DESPORTIVA}

Dos 1.818 alunos da nossa amostra, 524 (28,8\%) praticam desporto federado (54 alunos não responderam a esta questão) e $396(21,8 \%)$ desporto escolar (29 alunos não responderam a esta questão), todos com pelo menos um ano de prática. $\mathrm{O}$ desporto federado supera, em número de praticantes, o desporto escolar.

Ao analisarmos o género dos alunos que praticam desporto (ver Tabela 1) verificamos que este grupo é constituído mais por 
rapazes do que por raparigas e as diferenças são significativas tanto no desporto federado ( $\mathrm{p}$ ?0,001) como no escolar ( $\mathrm{p} ? 0,05)$.

Tabela 1 - Género dos desportistas federados e escolares

\begin{tabular}{|c|c|c|c|c|c|c|c|c|c|}
\hline \multirow{3}{*}{\multicolumn{2}{|c|}{ Prática desportiva }} & \multicolumn{4}{|c|}{ Desporto federado } & \multicolumn{4}{|c|}{ Desporto Escolar } \\
\hline & & \multicolumn{2}{|c|}{ não pratica } & \multicolumn{2}{|c|}{ pratica } & \multicolumn{2}{|c|}{ não pratica } & \multicolumn{2}{|c|}{ pratica } \\
\hline & & $\mathrm{n}$ & $\%$ & $\mathrm{n}$ & $\%$ & $\mathrm{n}$ & $\%$ & $\mathrm{n}$ & $\%$ \\
\hline \multirow[t]{4}{*}{ Género } & \multirow{4}{*}{$\begin{array}{l}\text { Feminino } \\
\text { Masculino } \\
\text { Total } \\
p \text {-value }\end{array}$} & 729 & $58,8 \%$ & 164 & $31,3 \%$ & 719 & $51,6 \%$ & 181 & $45,7 \%$ \\
\hline & & 511 & $41,2 \%$ & 360 & $68,7 \%$ & 674 & $48,4 \%$ & 215 & $54,3 \%$ \\
\hline & & 1240 & $100,0 \%$ & 524 & $100,0 \%$ & 1393 & $100,0 \%$ & 396 & $100,0 \%$ \\
\hline & & & & &, $000 * * *$ & & & & ,038* \\
\hline
\end{tabular}

Nota: * p ? 0,05** p ? 0,01*** p ? 0,001

Contudo, no desporto escolar ainda existe um certo equilíbrio entre géneros, $54,3 \%$ de rapazes para $45,7 \%$ de raparigas, mas no desporto federado a desproporcionalidade é mais notória, 68,7\% rapazes e $31,3 \%$ raparigas.

Procedemos à análise das modalidades praticadas pelos desportistas da amostra, assentes no pressuposto de que a natureza e as características dos desportos escolhidos pelos jovens talvez influam, de forma distinta, nos relacionamentos entre pares e ajudem a explicar a associação destes jovens desportistas com as situações de bullying ocorridas na escola.

Para este intento considerámos que seria mais producente organizar por grupos as modalidades presentes nos questionários, em função das suas características principais, do que descriminar todas as modalidades encontradas. Utilizou-se a seguinte sistematização das atividades desportivas: 0 - não praticante; 1 desporto individual; 2 - desporto coletivo; 3 - desporto de combate; 4 - desporto de oposição (e.g. ténis, badminton, etc.); e 5 - desporto de evasão (e.g. os chamados desportos "radicais", de grandes espaços ou realizados na natureza).

Os resultados obtidos podem ser observados na Tabela 2 e na Figura 1, apresentadas de seguida. 
Tabela 2 - Sistematização das atividades desportivas praticadas

\begin{tabular}{|l|r|rr|r|}
\hline \multirow{2}{*}{ Categorias } & \multicolumn{2}{|c}{ Desporto Federado } & \multicolumn{2}{c|}{ Desporto Escolar } \\
\cline { 2 - 5 } & $\mathrm{n}$ & \multicolumn{1}{c|}{$\%$} & \multicolumn{1}{c|}{$\mathrm{n}$} & \multicolumn{1}{c|}{ \% } \\
\hline não praticante & 1240 & 70,3 & 1393 & 77,9 \\
\hline Desportos individuais & 108 & 6,1 & 90 & 5,0 \\
\hline Desportos coletivos & 313 & 17,7 & 263 & 14,7 \\
\hline Desportos de combate & 17 & 1,0 & 1 &, 1 \\
\hline Desportos de oposição & 49 & 2,8 & 42 & 2,3 \\
\hline Desportos de evasão & 37 & 2,1 & 0 & 0 \\
\hline Total & 1764 & 100,0 & 1789 & 100,0 \\
\hline
\end{tabular}

Figura 1 - Sistematização das atividades desportivas praticadas

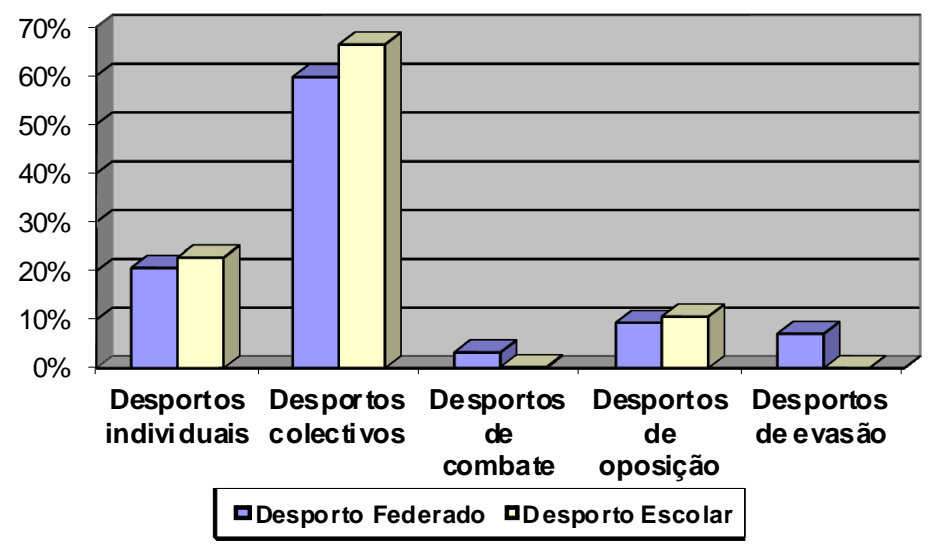

A partir dos dados constatamos que a grande preferência desportiva dos alunos recai sobre os denominados desportos coletivos (e.g. futebol, andebol, basquetebol, voleibol, etc.). Em contexto federado estes desportos ocupam 59,7\% $(n=313)$ de toda a prática registada e em contexto escolar a sua parcela é ainda superior, 66,4\% $(n=263)$. Entre os desportos coletivos praticados, o futebol é de facto predominante na população estudada porque ocupa uma parcela de $60,7 \%(n=190)$, entre os desportos coletivos federados e 48,6\% $(\mathrm{n}=128)$, entre os desportos coletivos escolares. O futebol abarca por si só, $36,2 \%(n=190)$ de toda a prática federada observada e $32,3 \%(\mathrm{n}=128)$ da respetiva prática escolar. 
Os resultados obtidos sobre os desportos mais praticados levamnos a crer que a questão do género dos praticantes é um aspeto que deve ser novamente analisado. Os rapazes, com maior percentagem de participação federada, estão igualmente em maioria em quase todos os grupos de modalidades com exceção dos desportos individuais, os quais são praticados principalmente por raparigas $(58,3 \% ; n=63)$. A hegemonia masculina acentua-se principalmente nos desportos coletivos $(81,2 \% ; n=254)$ e nos desportos de combate $(70,6 \% ; n=17)$. Na modalidade de futebol chega a atingir uma percentagem de 94,7\% ( $n=180)$. Modalidades como a natação e a ginástica rítmica são as que recolhem maior preferência entre as raparigas da nossa amostra.

No desporto escolar o cenário é semelhante ao anterior com a exceção de que nos desportos coletivos a diferença entre géneros diminui um pouco - de 4 rapazes para 1 rapariga, passamos a 2 rapazes para 1 rapariga - ainda assim, na modalidade de futebol a participação masculina atinge os $85,2 \%(n=109)$. Nos desportos individuais a diferença aumenta a favor das raparigas $(88,9 \%$; $=80)$, na proporção de quase nove para cada rapaz praticante.

\subsection{Prática desportiva e enVolvimento em BULlying}

As situações de bullying a que nos referimos nesta pesquisa ocorreram na escola ou em contexto escolar durante o período estudado mas podem não estar relacionadas direta ou indiretamente com qualquer atividade desportiva, escolar ou federada.

\subsubsection{PRÁtICA DESPORTIVA FEDERAdA E VITIMIZAÇÃO POR BULLYING NA ESCOLA}


Tabela 3 - Incidência da vitimização entre não praticantes e praticantes federados

\begin{tabular}{|c|c|c|c|c|c|c|}
\hline & \multicolumn{2}{|c|}{ Vitimização na escola } & \multirow{2}{*}{ Total } & \multirow{2}{*}{$\begin{array}{c}\chi^{2} \\
p \text {-value }\end{array}$} \\
\hline & & & não vitimados & vitimados & & \\
\hline \multirow[t]{4}{*}{ Desporto federado } & \multirow[t]{2}{*}{ não pratica } & $\mathrm{n}$ & 835 & 405 & 1240 & \multirow[t]{4}{*}{, $000 * * *$} \\
\hline & & $\%$ & $67,3 \%$ & $32,7 \%$ & $100,0 \%$ & \\
\hline & \multirow[t]{2}{*}{ pratica } & $\mathrm{n}$ & 397 & 127 & 524 & \\
\hline & & $\%$ & $75,8 \%$ & $24,2 \%$ & $100,0 \%$ & \\
\hline \multirow{2}{*}{\multicolumn{2}{|c|}{ Total }} & $\mathrm{n}$ & 1232 & 532 & 1764 & \\
\hline & & $\%$ & $69,8 \%$ & $30,2 \%$ & $100,0 \%$ & \\
\hline
\end{tabular}

Nota: * p ? 0,05 ** p ? 0,01 *** p ? 0,001

Na tabela 3, verificamos que a proporção de alunos vitimados pelo bullying é significativamente menor entre os jovens que praticam desporto federado, por um período de tempo igual ou superior a 1 ano, 24,2\% ( $\mathrm{n}=127)$, do que entre aqueles que não o fazem, 32,7\% $(\mathrm{n}=405)$. Os jovens que participam no desporto federado parecem assim mais protegidos das situações de bullying que ocorrem em ambiente escolar.

Tabela 4 - Incidência da vitimização entre os praticantes de desportos federados

\begin{tabular}{|c|c|c|c|c|c|}
\hline \multirow{2}{*}{\multicolumn{2}{|c|}{ Modalidades federadas }} & \multicolumn{2}{|c|}{ Vitimização na escola } & \multirow{4}{*}{$\begin{array}{r}\text { Total } \\
1240 \\
100,0 \%\end{array}$} & \multirow{4}{*}{$\begin{array}{c}\chi^{2} \\
-\end{array}$} \\
\hline & & \multirow{3}{*}{$\begin{array}{r}\text { não vitimados } \\
835 \\
67,3 \%\end{array}$} & \multirow{3}{*}{$\begin{array}{r}\text { vitimados } \\
405 \\
\mathbf{3 2 , 7 \%}\end{array}$} & & \\
\hline \multirow[t]{2}{*}{ não praticante federado } & $\mathrm{n}$ & & & & \\
\hline & $\%$ & & & & \\
\hline \multirow[t]{2}{*}{ Desportos individuais } & $\mathrm{n}$ & 78 & 30 & 108 & \multirow{2}{*}{,298 } \\
\hline & $\%$ & $72,2 \%$ & $27,8 \%$ & $100,0 \%$ & \\
\hline \multirow[t]{2}{*}{ Desportos coletivos } & $\mathrm{n}$ & 242 & 71 & 313 & \multirow{2}{*}{, $001 * * *$} \\
\hline & $\%$ & $77,3 \%$ & $22,7 \%$ & $100,0 \%$ & \\
\hline \multirow[t]{2}{*}{ Desportos de combate } & $\mathrm{n}$ & 16 & 1 & 17 & \multirow{2}{*}{,019* } \\
\hline & $\%$ & $94,1 \%$ & $5,9 \%$ & $100,0 \%$ & \\
\hline \multirow[t]{2}{*}{ Desportos de oposição } & $\mathrm{n}$ & 37 & 12 & 49 & \multirow{2}{*}{,230 } \\
\hline & $\%$ & $75,5 \%$ & $24,5 \%$ & $100,0 \%$ & \\
\hline \multirow[t]{2}{*}{ Desportos de evasão } & $\mathrm{n}$ & 24 & 13 & 37 & \multirow{2}{*}{,752 } \\
\hline & $\%$ & $64,9 \%$ & $35,1 \%$ & $100,0 \%$ & \\
\hline \multirow[t]{2}{*}{ Total } & $\mathrm{n}$ & 1232 & 532 & 1764 & \\
\hline & $\%$ & $69,8 \%$ & $30,2 \%$ & $100,0 \%$ & \\
\hline
\end{tabular}

Nota: * p ? 0,05**p? 0,01*** p ? 0,001 
Ao aprofundarmos a análise verificamos que a redução do número de vítimas é significativa apenas nos desportos coletivos (p?0,001) e de combate ( $\mathrm{p} ? 0,05)$. Nas restantes modalidades não aparenta existir o mesmo efeito face ao bullying (ver Tabela 4).

6.2.2 PRÁtICA DESPORTIVA ESCOLAR E VITIMIZAÇÃO POR BULLYING NA ESCOLA

Tabela 5 - Incidência da vitimização entre não praticantes e praticantes escolares

\begin{tabular}{|l|l|c|rrr|r|}
\hline \multicolumn{2}{|c|}{} & \multicolumn{2}{|c|}{$\begin{array}{c}\text { Vitimização na escola } \\
\text { não vitimados }\end{array}$} & vitimados & Total & $X^{2}$ \\
p-value
\end{tabular}

Constatamos na Tabela 5 que a participação no desporto escolar, ao contrário do desporto federado, não parece proteger os jovens do bullying, inclusivamente, parece expô-los um pouco mais a este problema. A proporção de alunos vitimados pelo bullying é significativamente maior entre os jovens que praticam desporto escolar, 34,3\% ( $\mathrm{n}=136)$, do que entre aqueles que não o fazem, 29,0\% $(n=404)$.

Analisando grupo a grupo de modalidades (ver Tabela 6), confirmamos que entre os praticantes dos desportos individuais $(43,3 \% ; p ? 0,01)$ e de oposição $(47,6 \%$; p?0,01) existe uma significativa maior prevalência da vitimização por bullying. 
Tabela 6 - Incidência da vitimização entre os praticantes de desportos escolares

\begin{tabular}{|c|c|c|c|c|c|}
\hline \multirow{2}{*}{\multicolumn{2}{|c|}{ Modalidades escolares }} & \multicolumn{2}{|c|}{ Vitimização na escola } & \multirow{4}{*}{$\begin{array}{r}\text { Total } \\
1393 \\
100,0 \%\end{array}$} & \multirow{4}{*}{$\begin{array}{l}X^{2} \\
-\end{array}$} \\
\hline & & \multirow{3}{*}{$\begin{array}{r}\text { não vitimados } \\
989 \\
71,0 \%\end{array}$} & \multirow{3}{*}{$\begin{array}{r}\text { vitimados } \\
404 \\
29,0 \%\end{array}$} & & \\
\hline \multirow[t]{2}{*}{ não praticante escolar } & $\mathrm{n}$ & & & & \\
\hline & $\%$ & & & & \\
\hline \multirow[t]{2}{*}{ Desportos individuais } & $\mathrm{n}$ & 51 & 39 & 90 & \multirow{2}{*}{, $004 * *$} \\
\hline & $\%$ & $56,7 \%$ & $43,3 \%$ & $100,0 \%$ & \\
\hline \multirow[t]{2}{*}{ Desportos coletivos } & $\mathrm{n}$ & 187 & 76 & 263 & \multirow{2}{*}{,973 } \\
\hline & $\%$ & $71,1 \%$ & $28,9 \%$ & $100,0 \%$ & \\
\hline \multirow[t]{2}{*}{ Desportos de combate } & $\mathrm{n}$ & 0 & 1 & 1 & \multirow{2}{*}{-} \\
\hline & $\%$ &, $0 \%$ & $100,0 \%$ & $100,0 \%$ & \\
\hline \multirow[t]{2}{*}{ Desportos de oposição } & $\mathrm{n}$ & 22 & 20 & 42 & \multirow{2}{*}{$009 * *$} \\
\hline & $\%$ & $52,4 \%$ & $47,6 \%$ & $100,0 \%$ & \\
\hline \multirow[t]{2}{*}{ Total } & $\mathrm{n}$ & 1249 & 540 & 1789 & \\
\hline & $\%$ & $69,8 \%$ & $30,2 \%$ & $100,0 \%$ & \\
\hline
\end{tabular}

Nota: * p ? $0,05 * * \mathrm{p} ? 0,01 * * * \mathrm{p} ? 0,001$

\subsubsection{PRÁtica DESPORTIVA FEDERADA E AGRESSÃO POR BULLYING NA ESCOLA}

Tabela 7- Incidência da agressão entre não praticantes e praticantes federados

\begin{tabular}{|c|c|c|c|c|c|c|}
\hline & & \multicolumn{2}{|c|}{ Agressão na escola } & \multirow{2}{*}{ Total } & \multirow{2}{*}{$\begin{array}{c}\mathrm{X}^{2} \\
p \text {-value }\end{array}$} \\
\hline & & & não agrediram & agrediram & & \\
\hline \multirow[t]{4}{*}{ Desporto federado } & \multirow[t]{2}{*}{ não pratica } & $\mathrm{n}$ & 886 & 354 & 1240 & \multirow[t]{6}{*}{, 402} \\
\hline & & $\%$ & $71,5 \%$ & $28,5 \%$ & $100,0 \%$ & \\
\hline & \multirow[t]{2}{*}{ pratica } & $\mathrm{n}$ & 364 & 160 & 524 & \\
\hline & & $\%$ & $69,5 \%$ & $30,5 \%$ & $100,0 \%$ & \\
\hline \multirow{2}{*}{\multicolumn{2}{|c|}{ Total }} & $\mathrm{n}$ & 1250 & 514 & 1764 & \\
\hline & & $\%$ & $70,9 \%$ & $29,1 \%$ & $100,0 \%$ & \\
\hline
\end{tabular}

A participação dos jovens no desporto federado não parece ter uma relação com os seus níveis de agressão/bullying (ver Tabela 7). $\mathrm{O}$ valor relativo de agressores entre jovens que não estão no desporto federado, 28,5\% ( $n=354)$, não difere significativamente da proporção de agressores entre os alunos com essa experiência desportiva (por 
um período de tempo igual ou superior a 1 ano), 30,5\% (n=160). A análise mais específica pelos diversos desportos praticados confirma que não existem diferenças significativas no número de alunos que praticaram agressões/bullying.

\subsubsection{PRÁticA DESPORTIVA ESCOLAR E AGRESSÃO POR BULLYING NA ESCOLA}

Tabela 8 - Incidência da agressão entre não praticantes e praticantes escolares

\begin{tabular}{|c|c|c|c|c|c|c|}
\hline & \multicolumn{2}{|c|}{ Agressão na escola } & \multirow{2}{*}{ Total } & \multirow{2}{*}{$\begin{array}{c}\chi^{2} \\
p \text {-value }\end{array}$} \\
\hline & & & não a gredir am & agrediram & & \\
\hline \multirow[t]{4}{*}{ Desporto Escolar } & \multirow[t]{2}{*}{ não pratica } & $\mathrm{n}$ & 1014 & 379 & 1393 & \multirow[t]{6}{*}{, $001 * *$} \\
\hline & & $\%$ & $72,8 \%$ & $27,2 \%$ & $100,0 \%$ & \\
\hline & \multirow[t]{2}{*}{ pratica } & $\mathrm{n}$ & 254 & 142 & 396 & \\
\hline & & $\%$ & $64,1 \%$ & $35,9 \%$ & $100,0 \%$ & \\
\hline \multirow{2}{*}{\multicolumn{2}{|c|}{ Total }} & $\mathrm{n}$ & 1268 & 521 & 1789 & \\
\hline & & $\%$ & $70,9 \%$ & $29,1 \%$ & $100,0 \%$ & \\
\hline
\end{tabular}

Contrariamente ao que sucede com o desporto federado, a participação no desporto escolar tem uma relação estatisticamente significativa com os comportamentos agressivos através de bullying (ver Tabela 8). Existem mais agressores/bullies entre os alunos participantes no desporto escolar do que entre os alunos que não estão envolvidos nesta atividade extracurricular. Ao verificar a situação ao nível dos grupos de modalidades sistematizados observouse que em todos existem maiores percentagens de alunos que agrediram/bullied, mas apenas no grupo dos desportos coletivos existe um acréscimo significativo $(35,7 \% ; \mathrm{p} ? 0,01)$.

\section{Discussão dOS RESULTADOS}

A discrepância entre géneros encontrada na prática desportiva em geral significa que na população estudada, as raparigas estão mais arredadas dos espaços desportivos e que os rapazes parecem mais propensos às atividades físicas e desportivas. Contudo, se o desporto federado superou o escolar em número de praticantes, em 
termos da maior democraticidade das atividades desportivas baseada no género, o desporto escolar apresenta resultados mais equilibrados.

Se por um lado, parece-nos que os rapazes preferem desportos em que o trabalho de equipa é fundamental, as raparigas parecem optar pelas modalidades individuais, nas quais, a qualidade do seu desempenho não está tão dependente da colaboração com outros colegas. Desportos como a natação e a ginástica rítmica são as que recolhem maior preferência entre as jovens da nossa amostra.

Sintetizando os resultados, podemos referir que encontramos menos alunos vitimados por bullying entre os jovens que praticam desporto federado, sobretudo desportos coletivos e de combate, mas o mesmo não se verificou entre os praticantes do desporto escolar. Neste contexto até encontramos mais vítimas entre os praticantes de desportos individuais e de oposição (e.g. ténis, badminton). Já ao nível da agressão/bullying, não se regista uma redução deste comportamento entre os praticantes do desporto federado (como seria esperado) e existe mesmo um acréscimo significativo entre os praticantes do desporto escolar, especialmente nos desportos coletivos que se desenvolvem na escola.

Em consequência das análises mais específicas constatamos que o facto da prática desportiva da nossa amostra registar acentuadas assimetrias na participação de rapazes e raparigas e na distribuição dos praticantes pelas diferentes modalidades, poderá condicionar o efeito socializador do desporto na redução dos comportamentos de bullying em contexto escolar. Quase dois em cada três desportistas praticam as denominadas modalidades colectivas, um em cada três desportistas pratica a modalidade de futebol e estas modalidades dominantes são maioritariamente praticadas por rapazes.

\subsection{PRÁtica deSPORTIVA E VITIMIZAÇÃO POR BULLYING}

A inter-relação entre a prática desportiva e a vitimização por bullying caracteriza-se por um significativo "efeito protector" do desporto federado $(\mathrm{p} ? 0,001)$ e por uma ausência desse efeito 
atenuador no desporto escolar. Estes resultados estão de acordo com Peguero (2008), segundo o qual, a participação em atividades extracurriculares pode ser um fator de proteção em relação ao bullying, quando estas decorrem fora da escola que o aluno frequenta e um fator de risco quando estas decorrem no seu interior. Tal como referido anteriormente, o autor sugere que os alunos que passam mais tempo na escola têm mais possibilidades de serem vitimados por bullying.

O facto de existirem menos vítimas de bullying entre os praticantes do desporto federado, pode significar que estes jovens são mais confiantes nas suas capacidades e socialmente mais aptos para interagir assertivamente com os seus pares (do que os colegas que não possuem esta vivência desportiva). Possivelmente a mudança de ambiente e de relacionamentos ajudam alguns jovens a sair do ciclo vicioso de bullying/vitimização que vivem na escola (Olweus, 1993). Infelizmente o desporto escolar não está a exercer o mesmo efeito redutor sobre a vitimização, o que pode querer dizer que os seus praticantes não estão a beneficiar do mesmo desenvolvimento pessoal e social. As causas para esta diferença devem ser investigadas para compreendermos o que eventualmente estará a faltar no treino desportivo que ocorre em contexto escolar.

Contudo, alguns resultados anteriormente apresentados podem impelir-nos a responder a esta pergunta a partir de outra perspetiva. Uma perspetiva menos penalizante para o desporto, no sentido em que diminui a sua responsabilidade na falta de um maior efeito atenuador sobre o bullying e que assenta na influência da variável género nos resultados encontrados.

O desporto escolar dispõe de um maior equilíbrio em relação ao género dos seus praticantes, enquanto no desporto federado existem claramente mais rapazes do que raparigas. Sendo as vítimas de bullying da nossa amostra, maioritariamente raparigas $(31,7 \%$ para $28,7 \%$ dos rapazes), talvez exista realmente maior probabilidade de encontrarmos vítimas entre os praticantes escolares do que entre os praticantes federados. Esta hipótese é reforçada pelo facto dos 
desportos coletivos federados serem pouco frequentados pelas raparigas $(18,8 \%)$ e da presença feminina ser muito mais relevante, por exemplo, nos desportos individuais de âmbito escolar $(88,9 \%)$.

Relativamente às agressões por bullying, nenhum dos contextos desportivos, federado ou escolar, parece favorecer as condições necessárias para a dissuasão destes comportamentos entre os seus praticantes, porém, no desporto escolar, a dificuldade em transmitir valores e competências sociais que poderiam contribuir para a dissuasão do comportamento bullying parece acrescida.

A interdependência registada entre a prática desportiva e a ocorrência de comportamentos agressivos de bullying traduz uma realidade muito preocupante. No contexto escolar existem mais alunos que agrediram/bullied entre os praticantes do que entre os não praticantes, sendo essa diferença estatisticamente significativa (p?0,01). Podemos então questionar se o desporto escolar "atrai" estes alunos e como é que eles se integram tão facilmente neste espaço de aprendizagem desportiva.

Em nossa opinião e com base nos dados que dispomos, para esta situação contribuem dois fatores: a predominância masculina nas referidas actividades e o facto de o futebol ser a modalidade mais praticada pelos jovens questionados: na nossa amostra o género masculino recorre mais ao bullying, como forma de agressão a um colega $(35,2 \%)$, do que o feminino $(23,1 \%$; p?0,001); por outro lado, as lacunas que parecem existir no processo de treino desportivo, relativamente ao desenvolvimento de relações positivas entre pares, poderão ser atribuídas maioritariamente a falhas no treino dos desportos coletivos e em especial no treino do futebol.

Recordamos que entre os desportos coletivos escolares, os rapazes constituem a maioria dos praticantes, $66,5 \%$, valor que sobe para os $85,2 \%$, na modalidade de futebol. Por sua vez, o futebol que se pratica nas escolas representa quase metade $(48,6 \%)$ dos respetivos desportos coletivos e um terço de toda a atividade desportiva escolar $(32,3 \%)$. De enfatizar que em contexto federado 
os valores denotam a mesma tendência mas embora exista um acréscimo semelhante de alunos que agridem, a diferença não chega a ser estatisticamente significativa.

O clima percepcionado pelo jovem no âmbito do treino de uma determinada modalidade - e que está dependente de aspetos como os valores existentes, as formas de relacionamento e comunicação, a supervisão da prática, etc. - pode reforçar a sua ligação a essa atividade ou levar ao seu abandono precoce. Deste modo, a maior percentagem de alunos que já cometeram atos de bullying, entre os praticantes das atividades desportivas analisadas, pode contribuir igualmente para que existam menos vítimas nos meandros do desporto federado, por exemplo. Frequentar atividades em que existem maiores probabilidades de confrontar colegas provocadores e agressivos, pode ter um efeito dissuasor nos jovens menos extrovertidos e confiantes. Em suma, uma atmosfera hostil para novos praticantes pode conduzir à sua não integração no grupo de trabalho e consequente afastamento da atividade desportiva.

\section{CONCLUSÕES}

Concluímos que se o efeito socializador do treino desportivo fosse claro e inequívoco, assistiríamos a um decréscimo evidente nas percentagens de vitimização e de agressão entre os alunos que usufruem desta vivência desportiva, independentemente do grau de participação de rapazes e raparigas e da modalidade praticada. A limitar um efeito mais positivo do desporto nesta investigação poderão estar, em nossa opinião, eventuais lacunas formativas ao nível do treino dos desportos coletivos, particularmente do futebol e na dinâmica de funcionamento do desporto escolar.

Talvez alguns conceitos ultrapassados e certos preconceitos enraizados estejam tradicionalmente associados à prática do futebol, assim como de outras modalidades, levando a ambientes pouco pacíficos entre pares e nada complacentes com a diferença. Por 
exemplo, o perpetuar de uma cultura relacionada com a "necessária" dureza e rudeza do futebolista (mesmo tratando-se de um jovem futebolista), passa muito pela falta de uma intervenção enérgica dos treinadores e professores a este nível. Igualmente responsáveis são as estruturas técnicas e dirigentes das instituições em que as práticas desportivas decorrem e os próprios encarregados de educação que muitas vezes são os primeiros a instigar condutas e atitudes menos solidárias por parte dos seus educandos. 
Sport, a means of preventing bullying at school? Abstract: This research aims to relate students' sports participation (school sports and federated sports) with their involvement in bullying situations. This is an analytical study of transversal delineation in a sample of 1.818 Portuguese students, with a mean age of 12.8 years. For the collection of data it was used a questionnaire adapted from Olweus (1989) that focuses on bullying behaviours. Topics on student's sport participation have been added.

We conclude that the influence of sports on bullying behaviour falls short of what was expected. Aspects such as students' gender and type of sports they practice clearly influence the results achieved.

Keywords: bullying. School. Sport. Bullies. victims

Deporte, una forma de prevenir el acoso
escolar?
Resumen: Su objetivo es investigar si la participación
deportiva de los estudiantes (escolar o federada)
disminuye la probabilidad de participación en el acoso
escolar durante la estancia en la escuela. Estudio
transversal analítico realizado sobre una muestra de
1818 estudiantes de las escuelas portuguesas, con
una edad media de 12,8 años. Se utilizó un cuestionario
sobre conductas de acoso, adaptado de Olweus
(1989), a los que se agregaron temas de la
participación deportiva de los estudantes. Llegamos a
la conclusión de que la influencia del deporte en este
nivel es menor de lo esperado, pero aspectos como el
género de los desportistas y el tipo de deportes que
se practican influyen claramente sobre los resultados
obtenidos
Palabras-clave: acoso escolar. Intimidación. Escuela.
Deporte. Víctima. agressor

Wovimento, Porto Alegre, v. 19, n. 02, p. 55-77, abr/jun de 2013. 


\section{REFERÊNCIAS}

COSTA, Paulo; PEREIRA, Beatriz; SILVÉRIO, Jorge. O papel da prática desportiva na promoção do espírito desportivo: estudo realizado com crianças e jovens praticantes e não praticantes de atividades desportivas. In: PEREIRA, Beatriz; CARVALHO, Graça. Atividade Física, Saúde e Lazer. Lisboa: Lidel, 2008. p. 431-449.

DUE, Pernille; HOLSTEIN, Bjorn Evald. Bullying victimization among 13 to 15 year old school children: Results from two comparative studies in 66 countries and regions. International Journal of Adolescent Medicine and Health, Tel Aviv, v. 20, n. 2, p. 209-221, apr./june 2008.

ENDRESEN, Inger; OLWEUS, Dan. Participation in power sports and antisocial involvement in preadolescent and adolescent boys. The Journal of Child Psychology and Psychiatry, London, v. 46, n. 5, p. 468-478, may 2005.

ESCURY, Annematt, DUDINKL, Ad. Bullying Beyond School: Examinating the Role of Sports. In: JIMERSON, Shane.; SWEARER, Susan; ESPELAGE, Dorothy. Handbook of Bullying in Schools: an International Perspetive. New York: Routledge, 2010. p. 235-248.

FELIX, Erika; GREEN, Jennifer. Popular girls and brawny boys - The role of gender in bullying and victimization experiences. In: JIMERSON, Shane.; SWEARER, Susan; ESPELAGE, Dorothy. Handbook of Bullying in Schools: an International Perspetive. New York: Routledge, 2010. p. 173-186.

HIGGINS, Catherine. How to improve the school ground enviroment as an antibullying strategy. In: SHARP, Sonia; SMITH, Peter. Tackling Bullying in Your School. London: Routledge, 1994. p. 133-173.

NETO, Alfredo. Interesses físicos no lazer: a influência do esporte de alto rendimento para a criança na relação lazer-escola-processo educativo. Dissertação (Mestrado) - Universidade de Campinas, Campinas, 1994.

OLWEUS, Dan. Bullying at School: what we know and what we can do. Oxford: Blackwell, 1993.

OLWEUS, Dan. Prevalence and incidence in the study of antissocial behavior: Definitions and measurement. In: KLEIN, M. Cross-national research in selfreported crime and delinquency. Dordrecht: Kluwer, 1989. p. 187-201.

PEGUERO, Anthony. Bullying Victimization and Extracurricular Activity. Journal of School Violence, United States, v. 7, n. 3, p. 71-85, 11 oct. 2008.

PEPLER, Debra et al. The development of bullying. International Journal of Adolescent Medicine and Health, Tel Aviv, v. 20, n. 2, p. 113-119, apr./june 2008

PEREIRA, Beatriz. Para uma escola sem violência: estudo e prevenção das práticas agressivas entre crianças. 2. ed. Lisboa: Calouste Gulbenkian, 2008. 
QUEIRÓS, Paula; GOMES, Paula; SILVA, Paula. Acerca dos valores no desporto. Acerca do futuro. In: PEREIRA, Beatriz; CARVALHO, Graça. Atividade Física, Saúde e Lazer. Lisboa: Lidel, 2008. p. 413-419.

SMITH, Peter; MONKS, Claire. Concepts of bullying: Developmental and cultural aspects. International Journal of Adolescent Medicine and Health, Tel Aviv, v. 20, n. 2, p. 101-112, apr./june 2008.

WOLKE, Dieter et al. Bullying involvement in primary school and common health problems. Archives of Disease in Childhood, London, v. 85, n. 3, p. 197-201, set. 2001.

Endereço para correspondência:

Fernando Marcelo Ornelas Melim

Secretaria Regional de Educação e Recursos Humanos,

Região Autónoma da Madeira/Centro de Investigação em Estudos da Criança (CIEC), Universidade do Minho, Braga, Portugal

Recebido em: 25.06.2012

Aprovado em: 03.01.2013

Vovimento, Porto Alegre, v. 19, n. 02, p. 55-77, abr/jun de 2013. 